\title{
Climate for Culture: assessing the impact of climate change on the future indoor climate in historic buildings using simulations
}

Johanna Leissner ${ }^{1 *+} \mathbb{B}$, Ralf Kilian ${ }^{1 \dagger}$, Lola Kotova ${ }^{2 \dagger}$, Daniela Jacob ${ }^{2 \dagger}$, Uwe Mikolajewicz $^{3 \dagger}$, Tor Broström ${ }^{4 \dagger}$, Jonathan Ashley-Smith ${ }^{5 \dagger}$, Henk L. Schellen ${ }^{6+}$, Marco Martens ${ }^{6 \dagger}$, Jos van Schijndel ${ }^{6 \dagger}$, Florian Antretter ${ }^{1 \dagger}$, Matthias Winkler ${ }^{1 \dagger}$, Chiara Bertolin ${ }^{7 \dagger}$, Dario Camuffo ${ }^{7 \dagger}$, Goran Simeunovic ${ }^{8+}$ and Tomáš Vyhlídal ${ }^{8+}$

\begin{abstract}
Background: The present study reports results from the large-scale integrated EU project "Climate for Culture". The full name, or title, of the project is Climate for Culture: damage risk assessment, economic impact and mitigation strategies for sustainable preservation of cultural heritage in times of climate change. This paper focusses on implementing high resolution regional climate models together with new building simulation tools in order to predict future outdoor and indoor climate conditions. The potential impact of gradual climate change on historic buildings and on the vast collections they contain has been assessed. Two moderate IPCC emission scenarios A1B and RCP 4.5 were used to predict indoor climates in historic buildings from the recent past until the year 2100 . Risks to the building and to the interiors with valuable artifacts were assessed using damage functions. A set of generic building types based on data from existing buildings were used to transfer outdoor climate conditions to indoor conditions using high resolution climate projections for Europe and the Mediterranean.

Results: The high resolution climate change simulations have been performed with the regional climate model REMO over the whole of Europe including the Mediterranean region. Whole building simulation tools and a simplified building model were developed for historic buildings; they were forced with high resolution climate simulations. This has allowed maps of future climate-induced risks for historic buildings and their interiors to be produced. With this procedure future energy demands for building control can also be calculated.

Conclusion: With the newly developed method described here not only can outdoor risks for cultural heritage assets resulting from climate change be assessed, but also risks for indoor collections. This can be done for individual buildings as well as on a larger scale in the form of European risk maps. By using different standardized and exemplary artificial buildings in modelling climate change impact, a comparison between different regions in Europe has become possible for the first time. The methodology will serve heritage owners and managers as a decision tool, helping them to plan more effectively mitigation and adaption measures at various levels.
\end{abstract}

Keywords: Climate change, High resolution climate modelling, Whole building simulation, Indoor climates, Damage and risk assessment

\footnotetext{
*Correspondence: johanna.leissner@zv.fraunhofer.de

${ }^{\dagger} J$ ohanna Leissner, Ralf Kilian, Lola Kotova, Daniela Jacob, Uwe

Mikolajewicz, Tor Broström, Jonathan Ashley-Smith, Henk L. Schellen,

Marco Martens, Jos van Schijndel, Florian Antretter, Matthias Winkler,

Chiara Bertolin, Dario Camuffo, Goran Simeunovic and Tomáš Vyhlídal

contributed equally to this work

1 Fraunhofer Gesellschaft, Hansastrasse 67c, 80686 Munich, Germany

Full list of author information is available at the end of the article
} provided you give appropriate credit to the original author(s) and the source, provide a link to the Creative Commons license, and indicate if changes were made. The Creative Commons Public Domain Dedication waiver (http://creativecommons.org/ publicdomain/zero/1.0/) applies to the data made available in this article, unless otherwise stated. 


\section{Background}

Climate change as well as the worldwide energy and resource deficiency problems are two very serious threats of our time. In order to manage sustainably our cultural heritage, it is important to know how future changes in climate will influence the outdoor and indoor climates in buildings. As a non-renewable resource of intrinsic importance to our identity, there is a need to develop more effective and efficient sustainable adaptation and mitigation strategies in order to preserve such cultural assets for the long-term future. More reliable assessments lead to better prediction models, which in turn enable preventive measures to be taken in a timely way, thus reducing the use of energy and resources. For this purpose the EU project "Climate for Culture" $[1,2]$ has implemented new high resolution climate change evolution scenarios with whole building simulation tools in order to identify the most urgent risks in Europe arising from climate change until the year 2100 . Thus, not only can the impact of climate change on historic buildings and future energy demands be estimated, but also the possible effects on the related indoor climates, in which valuable works of art are kept, can be evaluated [2]. Only a summary of the methodology (Fig. 1) and a selection of the results from the project, mainly in the areas of climate modelling, whole building simulation and damage and risks are included in this article. The reader is also referred to the so-called deliverables on the project website [3], as well to coming publications in appropriate journals.

\section{Climate change modelling and simulations}

The most of the observed increase in global average temperatures since the mid-20th century is very likely due to the observed increase in anthropogenic greenhouse gas (GHG) concentrations. The time-dependent (over centuries) climate response to changing concentration of GHGs can be studied using global circulation models (GCM). GCMs have been developed as a mathematical representation of the Earth system, which are not only coupled atmosphere-ocean general circulation models, but also take into account different biogeochemical feedbacks. Global climate models are forced with different future emission scenarios. These scenarios are developed by the Intergovernmental Panel on Climate Change (IPCC) and described for example how the future population will grow or which technologies will be applied to reduce $\mathrm{CO}_{2}$ emissions. Despite further development, current GCMs provide information only at a relative coarse spatial scale which is not sufficient for evaluating the impact of climate change on historic buildings. Thus high resolution regional climate models were needed. The regional climate model REMO [4] provided regional climate change projections for entire Europe at $12.5 \mathrm{~km}$ spatial resolution. Two moderate emission scenarios, the A1B scenario [5] and the very recent RCP4.5 scenario of the IPCC assessment report 5 (AR5) [6] were applied. For the mid-line $\mathrm{A} 1 \mathrm{~B}$ scenario, a $\mathrm{CO}_{2}$ emission increase is assumed until 2050 and a decrease afterwards. The second scenario-the RCP 4.5-stands for Representative
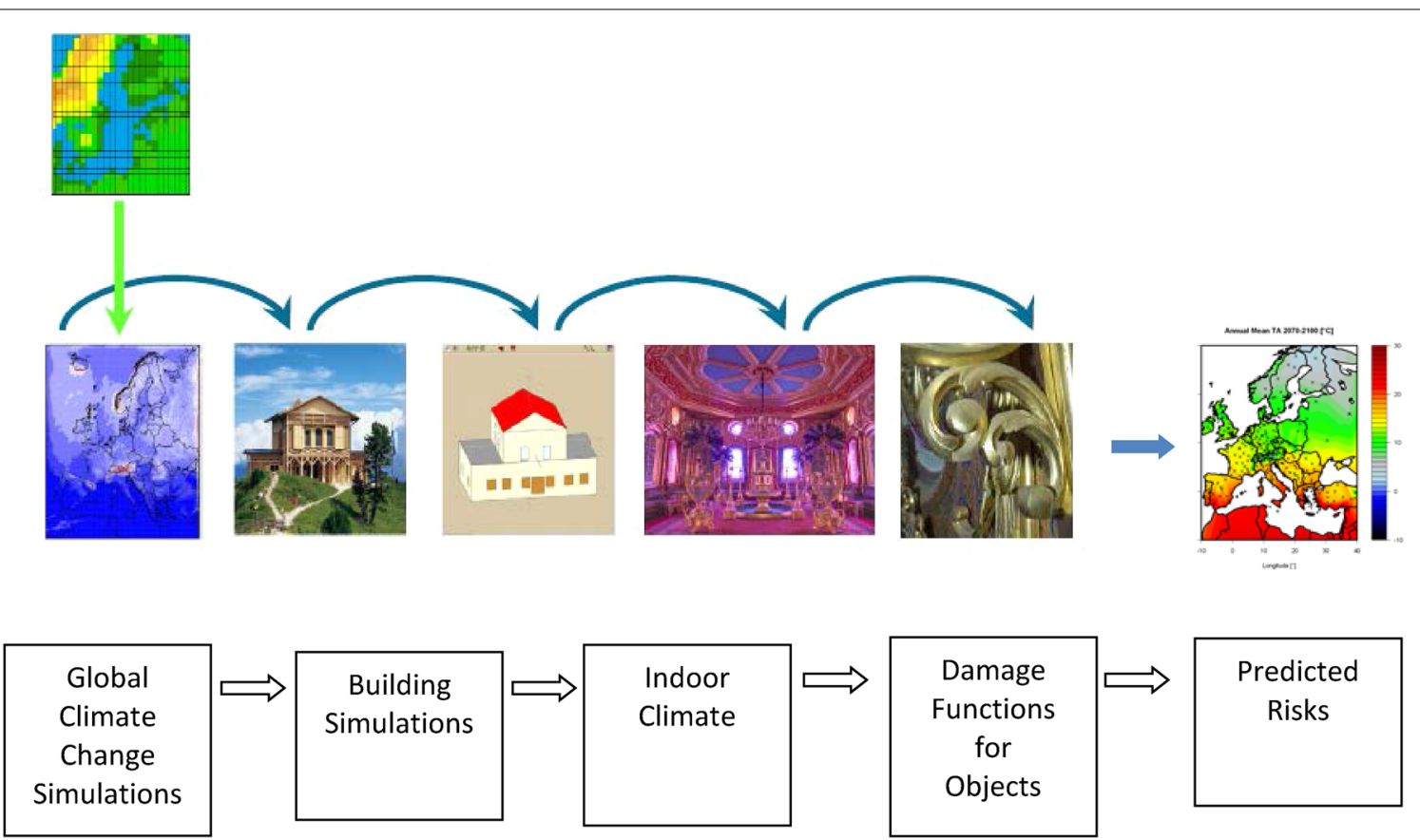

Fig. 1 The Climate for Culture method for risk assessment from climate change projections to individual risk assessment and risk maps 
Concentration Pathway (RCP) and is a scenario of longterm, global emissions of greenhouse gases, short-lived species, and land-use-land-cover which stabilizes radiative forcing at 4.5 Watts per meter squared $\left(\mathrm{W} / \mathrm{m}^{2}\right)$, approximately $650 \mathrm{ppm} \mathrm{CO}$ equivalent) in the year 2100 without ever exceeding that value.

Regional modeling allows more precise forecasts to be made in both time and space for the cultural heritage buildings. Besides temperature a whole set of climate parameters needed to be defined as input to whole building simulation tools (Table 1). This set of climate indices was calculated from the REMO simulations for two time periods 2021-2050 (near future) and 2071-2100 (far future). The period of 1961-1990 (recent past) was used as a reference period. Data with a hourly resolution has been made available for more than 900 locations. Selected locations were equally distributed over entire Europe and were placed in the center of each 12th grid box of the REMO model. Additionally all case study locations, and more than 300 locations (Fig. 2) where observational data was available for verification have been taken into account. The modelled climate data sets were extensively verified with observational data sets to check their applicability for hygrothermal whole building simulation. Systematic deviations and other issues related to the use of modelled climate data were identified.

\section{Building simulations}

The future indoor climate of buildings can be predicted using the data set of climate indices from the global climate simulations. For this purpose, tools were developed to model and simulate indoor climates of historic buildings through analysing the buildings, introducing various modelling steps and validating the model by real measurement data. Two approaches were followed: development of a full-scale multizone dynamic hygrothermal

\section{Table 1 Climate indices provided by climate modelling}

\begin{tabular}{ll}
\hline Value & Unit \\
\hline Temperature & ${ }^{\circ} \mathrm{C}$ \\
Relative humidity & $\%$ \\
Total precipitation (normal rain) & $\mathrm{mm}$ \\
Wind speed & $\mathrm{m} / \mathrm{s}$ \\
Wind direction & Degree \\
Global radiation & $\mathrm{W} / \mathrm{m}^{2}$ \\
Diffuse radiation & $\mathrm{W} / \mathrm{m}^{2}$ \\
Global counter radiation & $\mathrm{W} / \mathrm{m}^{2}$ \\
Cloud coverage & $\%$ \\
Ground temperature & ${ }^{\circ} \mathrm{C}$ \\
Ground reflectance & - \\
Air pressure & $\mathrm{Pa}$ \\
\hline
\end{tabular}



whole building simulation and a simplified hygrothermal building model. Moreover, computational fluid dynamics modelling tools have been applied to study the airflows in two case study rooms: the bed chamber in Linderhof Palace with the objective of validating the concept of forced ventilation based indoor-climate control and the Chapel of the Holy Cross in Karlštejn Castle with the purpose of detecting the most critical zones in the interior (see Fig. 3). For Linderhof Palace, a detailed hygrothermal simulation model of the bedchamber, was developed and validated with measurements of the indoor climate and air flow. With this hygrothermal model it was possible to study the impact of different ventilation concepts on indoor climate and energy consumption [7] and develop a multistage ventilation concept [8].

Whole building simulation models combine thermal building simulation with the hygrothermal component simulation. These models take into account the type of use (e.g. visitors, events) and HVAC (heating, ventilation and air conditioning) climatisation to assess the indoor environment. Different software tools have been systematically evaluated and the most useful ones for historic buildings were Hambase $[9,10]$ and WUFIplus $[8,11$, 12]. The results of hygrothermal whole building simulation cover the whole range of hourly energy demand for building conditioning for each zone, hourly indoor temperature and relative humidity for comfort and damage assessment as well as hygrothermal conditions on and 


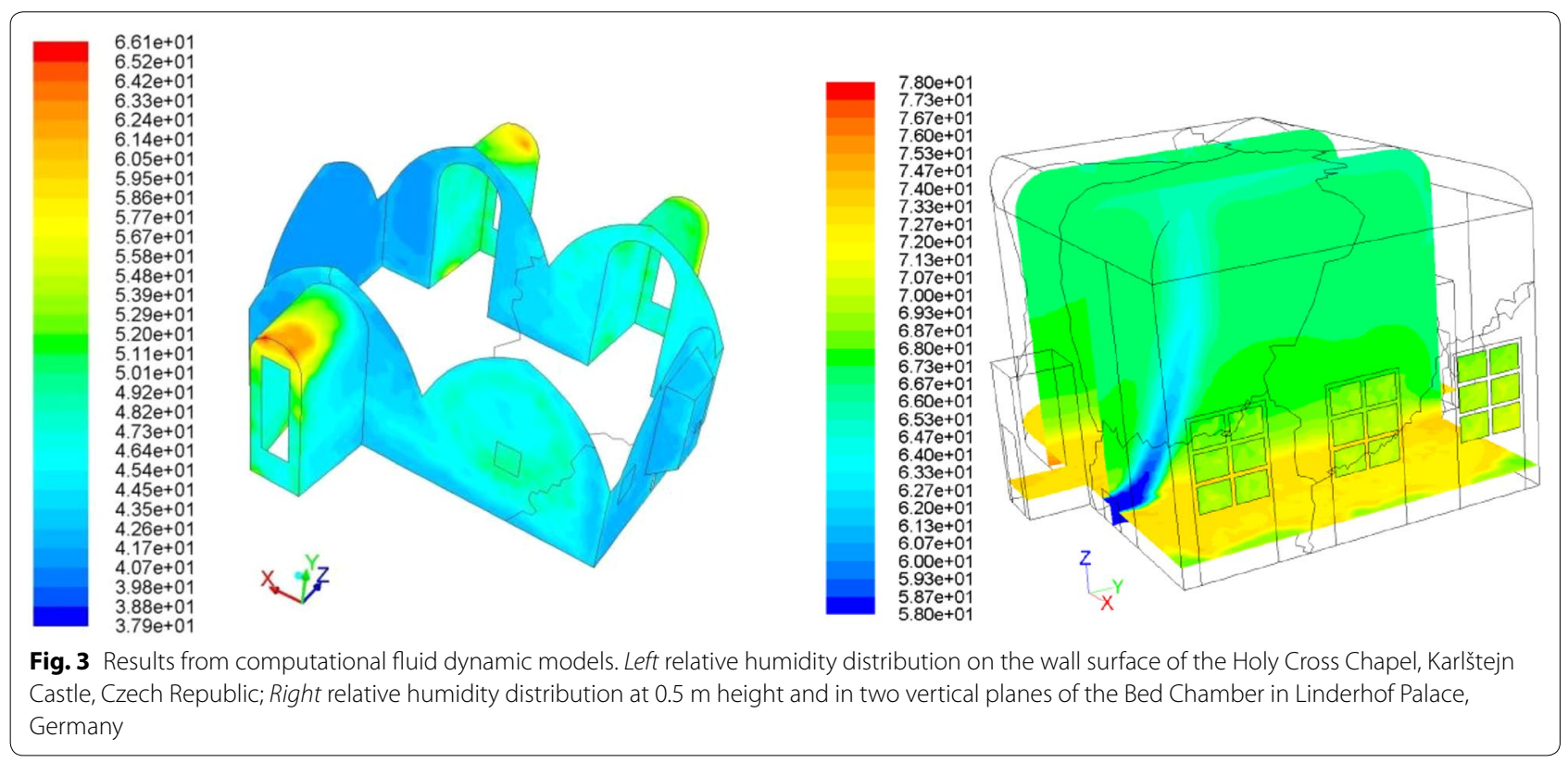

in the envelope components to assess hygric issues like mould growth [8]. Thus, the full building simulations give a better representation of the hygrothermal performance of the building but this is at a high cost of developing the model and relatively long times for computing.

A second but simplified approach using state-spacemodels as transfer functions between the outdoor and indoor conditions was also applied for the prediction of indoor temperature and relative humidity [13, 14]. The simplified hygrothermal building model is a simple mathematical function that calculates the indoor climate from the outdoor climate. The function is derived from a statistical analysis of measurements. This method can only be applied when all necessary measured values are available for parameterization of the model. But the simulation performance of this method is easier to set up and the computing time is so short that simulations can even be made online. This has made it possible to perform simulations for different generic building types on a fine grid over Europe for different time periods to produce indoor climate and indoor climate risk maps. So far, the simplified model is limited to buildings without active climate control.

\section{From outdoor climate simulation to future indoor climates and risk assessment} Outdoor climate predictions and outdoor risk maps

Climate change is mainly associated with the greenhouse gas carbon dioxide. The concentrations of $\mathrm{CO}_{2}$ in the atmosphere are increasing at an accelerating rate from decade to decade although many endeavours have been made to decrease the global emissions. The latest atmospheric $\mathrm{CO}_{2}$ data is consistent with a continuation of this long-standing trend and has reached $400.26 \mathrm{ppm}$ in February 2015 [15]. This is causing the planet to warm up and the earth's average temperature has risen by $0.8{ }^{\circ} \mathrm{C}$ over the past century. Climate model projections summarized in Assessment Report AR5 of the IPCC [16] indicated that during the 21 st century the global surface temperature is likely to rise a further $0.3-1.7^{\circ} \mathrm{C}$ for their lowest emission scenario using stringent mitigation and 2.6-4.8 ${ }^{\circ} \mathrm{C}$ for their highest. Even small changes in the average temperature can translate to large and potentially dangerous shifts in climate and weather. The main focus of this project was given to the gradual changes of climate change and not to extreme events: This was excluded for this study by the European Commission`s 2008 call for projects.

The main predictions from the high resolution regional climate modelling concerning the expected temperature differences in the near and far future with reference to the recent past, are discussed here and are based on two moderate emission scenarios. For the A1B emission scenario all these differences are positive (i.e. greater than zero, in mathematical terms) for the whole of Europe, with maximum changes in Northern Europe, in the inland of Northern Africa, centre of Spain, Greece and Turkey. Under the RCP4.5 emission scenario, this prediction is similar to A1B for the near future but however it simulates a decrease in temperature change for the last decades at the end of the century. Figure 4 shows projected changes of the annual mean of near-surface air temperature (TEMP2) for the far future. The temperature 


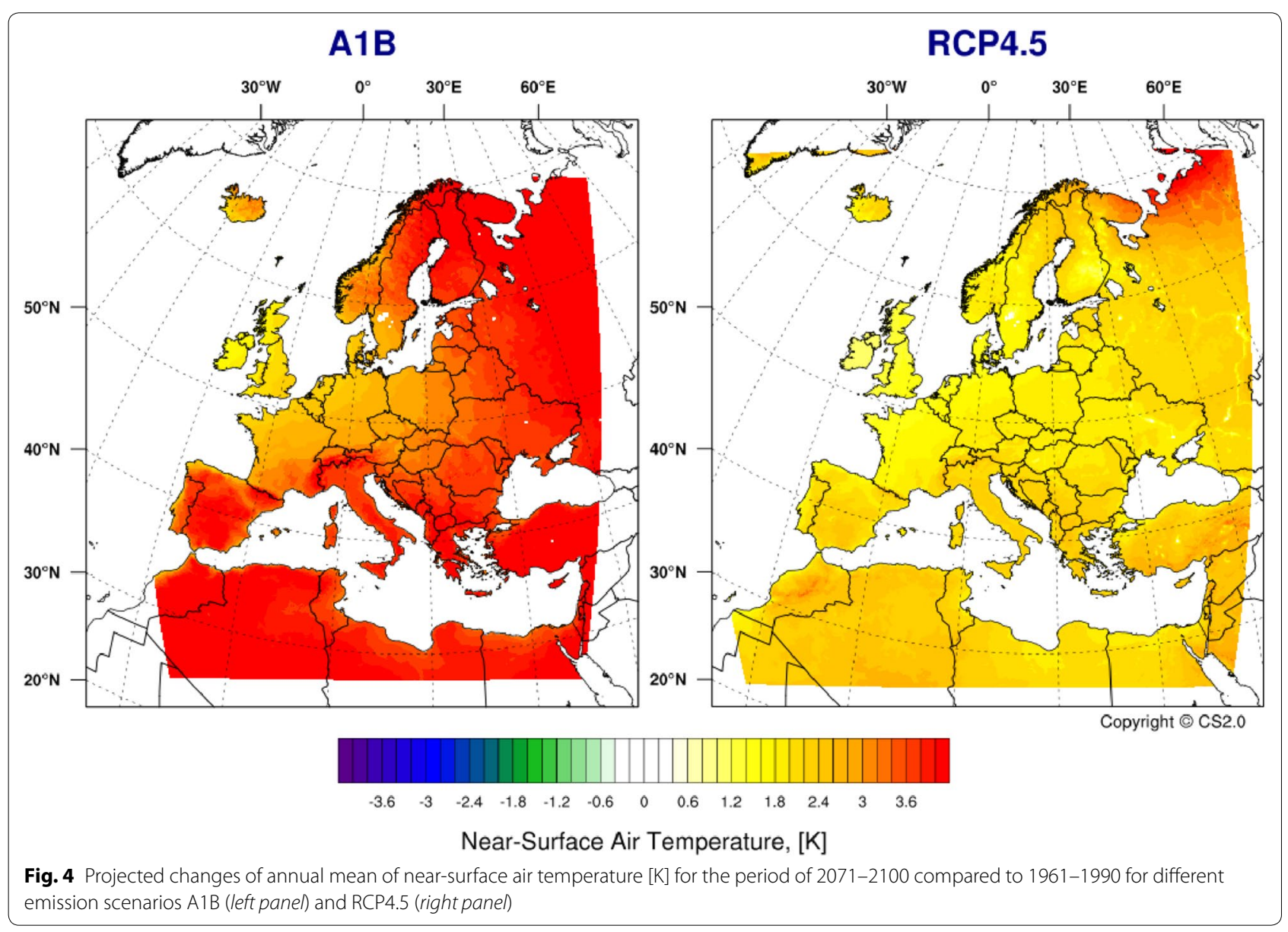

increase is statistically significant, with regional differences, for entire Europe for all simulations. While the temperature increases between 1 and $3{ }^{\circ} \mathrm{C}$ for RCP4.5, the A1B scenario's simulations showed projected future warming for a range of 2 and $4.5^{\circ} \mathrm{C}$. The projected spatial patterns are very similar in all scenarios with stronger annual mean warming in Southern Europe and towards the northeast.

Whereas TEMP2 rises, the REMO model does not give a clear signal with regard to precipitation (TPREC) for the whole of Europe. The results presented in Fig. 5 show that the general tendency is enhanced precipitation for most regions in central and northern Europe and decreased precipitation in the Mediterranean realm (up to $40 \%$ over Iberian Peninsula for A1B). Hatched areas indicate regions with statistically significant changes.

The expected changes in yearly total precipitation ( $\mathrm{mm} /$ year), in percentage terms, have been evaluated for the A1B emission scenario for the near and far future (Fig. 5, left and right). Both periods predict no or small changes from 0 to $20 \%$ in Northern Europe (i.e. European Russia, Poland and Scandinavian Peninsula) and
Central-Eastern Europe (i.e. Germany, Austria, Switzerland, Hungary, Czech Republic, Slovakia, and Ukraine). In the region of the European Atlantic Coast (i.e. Island, UK, Ireland and France) and Mediterranean regions the prediction highlights a mixed situation with both negative and positive changes up to $+50 \%$ in Egypt, Libya and Eastern Algeria and $-50 \%$ in central Portugal, Morocco and Western Algeria.

The outdoor climate such as wind-driven rain or snowfall or high temperatures has a strong influence on cultural heritage structures and surfaces and on the indoor environments in buildings. For example, high temperatures may be amplified in cities where most of cultural heritage is located because cities absorb more heat during the day than suburban and rural areas. Higher temperatures and more extreme events will likely affect the rate of degradation and the cost of climatisation (HVAC $=$ Heating, Ventilation, Air Conditioning) of buildings for stable climate conditions of art objects but also for human comfort and health in cities. Therefore, the future climate predictions were used to create different kinds of outdoor impact/risk maps [17] since they 


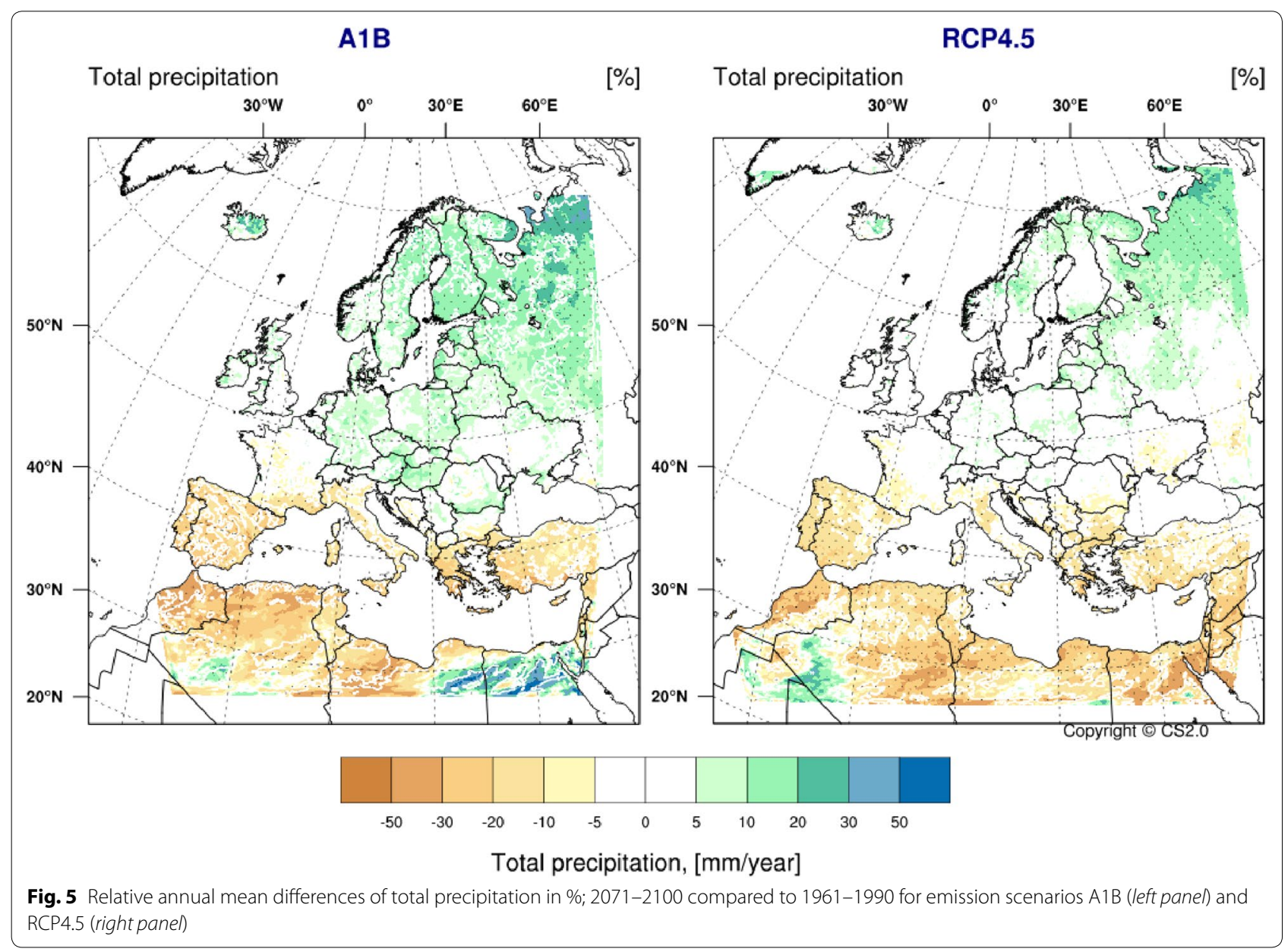

constitute a powerful tool for preventive conservation and policy makers. The assessment of impact and risk potentially caused by climate change has been evaluated for following 7 outdoor environmental variables under the two IPCC emission scenarios A1B and RCP4.5:

- Freeze-Thaw cycles

- Salt crystallization cycles

- Sea level rise

- Frost days index

- Dry days index

- Wet days index

- Heavy precipitation Index

- Tropical day index

One example discussed here is the tropical days index, i.e. the future change in respect to the recent past in the number of days with average $\mathrm{T}>20^{\circ} \mathrm{C}$ in a year (Fig. 6). This climate variable is useful to evaluate health risks for the population or for tourists visiting cultural heritage as well as the potential increase in energy consumption and enhancement of corrosion rates. The emission scenario A1B shows important changes in the far future, reaching a positive ( $>0$, in mathematical terms) increase up to +60 days/year homogeneously distributed over the whole Mediterranean region, especially on the coast of the Provence (France) and on the Black Sea coast. Extreme conditions with an increase up to +110 days/ year are expected on the Egyptian and Libyan coasts.

\section{Future indoor climates and risk assessment}

Implementing the climate change projections together with building simulations allows the production of future values of air temperature, relative humidity and humidity mixing ratio inside buildings. The simulated indoor climate has been evaluated with the newly developed automated method which assesses indoor climate variables as well as indoor damage and risk parameters for biological, chemical and mechanical damage [18, 19]. The geographical distribution of each assessed parameter for all time-windows is summarized and visualized with pan-European maps. Figure 7 shows the complete 


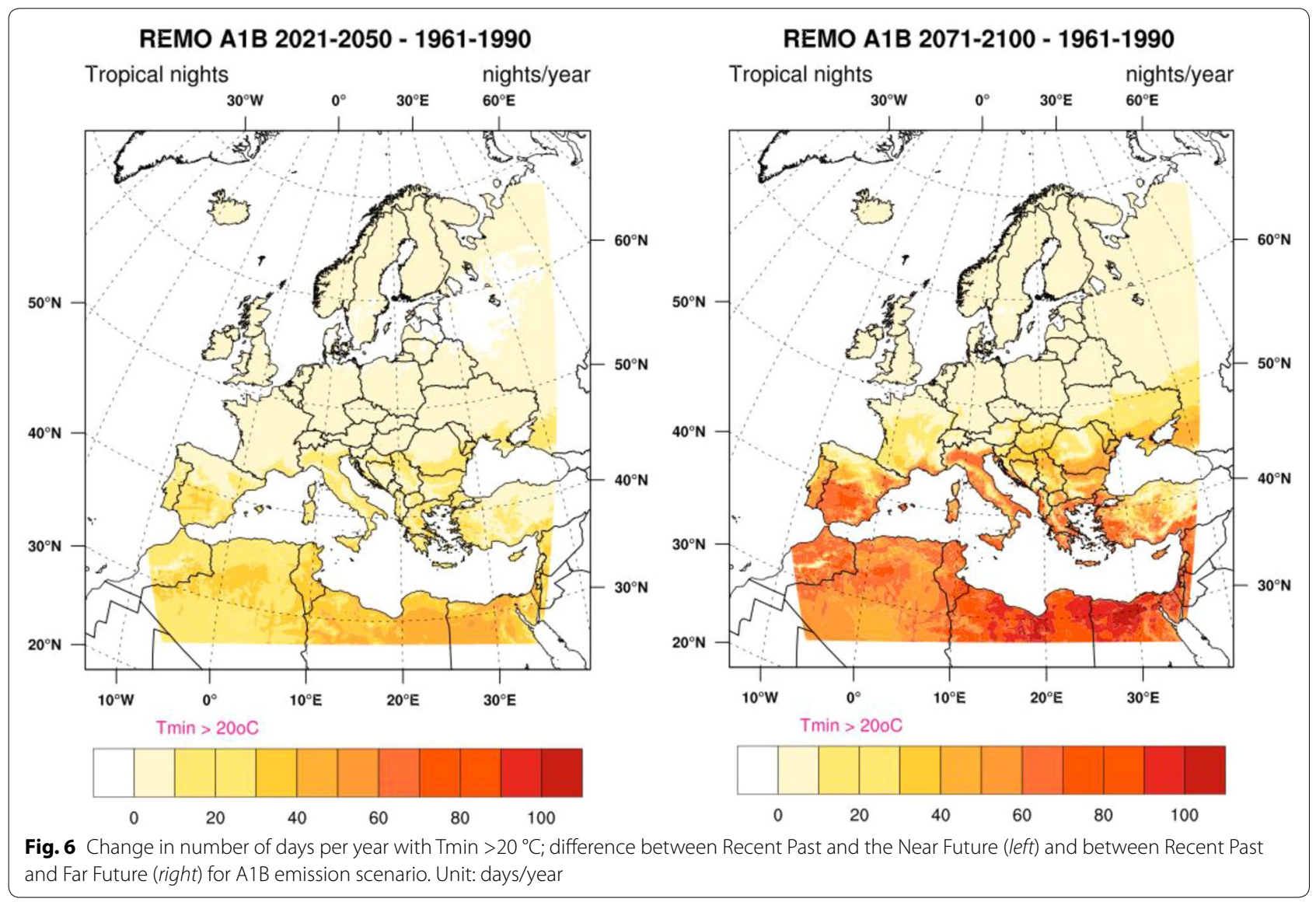

map-creation process, from defining a building model to plotting the maps. The various indoor risk maps are highlighting the most critical changes that will likely occur over Europe on cultural heritage materials for the near future period (2021-2050) and the far future period (2071-2100) in reference to the recent past period (1961-1990).

The automated method model was applied to 16 different generic building types which share the same rectangular layout but differ in size, window area, construction and moisture buffering capacity, see Fig. 8. They have been used to simulate the variations in indoor climate over the different European climate zones. Figure 9 reports the future difference in indoor temperature range for the building type 1 (i.e. heavyweight, small building with small window area and no climate control) in respect to the recent past.

Figure 9 highlights the geographical distribution of indoor temperature changes over the whole of Europe: An increase in temperature range can be expected in Sweden and Norway, Denmark, Holland, central Romania, the Alps, Italy, on the coast of the former Yugoslavia and Greece. The rest of Europe will experience a decrease in temperature range. In the far future the scenario changes a bit, with the identification of two macro-areas: the first is Northern Europe, comprising also Germany and Poland with a decrease in indoor temperature range up to $5{ }^{\circ} \mathrm{C}$ and the second area constituting the Western and Southern Europe, with an increase up to $4{ }^{\circ} \mathrm{C}$ in indoor temperature range.

Furthermore, the automated method is used to produce risk maps illustrating the risks for different kinds of buildings and the collections they contain. The predicted indoor climate is combined with different damage functions [20-29] to assess the risks deriving from climate change [30]. Figure 10 shows the procedure of the different steps from outdoor climate data to indoor climate data and to the assessment of risks by damage functions. The basis for the risk maps is formed by hygrothermal building simulations for three time periods: 1961-1990 (recent past), 2021-2050 (near future) and 2071-2100 (far future).

To assess the impact of climate change on the indoor climate of historical buildings statistical parameters of the three indoor climate variables temperature, relative humidity and mixing ratio were evaluated on annual and monthly time-scales. For all three variables the statistical parameters mean, maximum, minimum and 

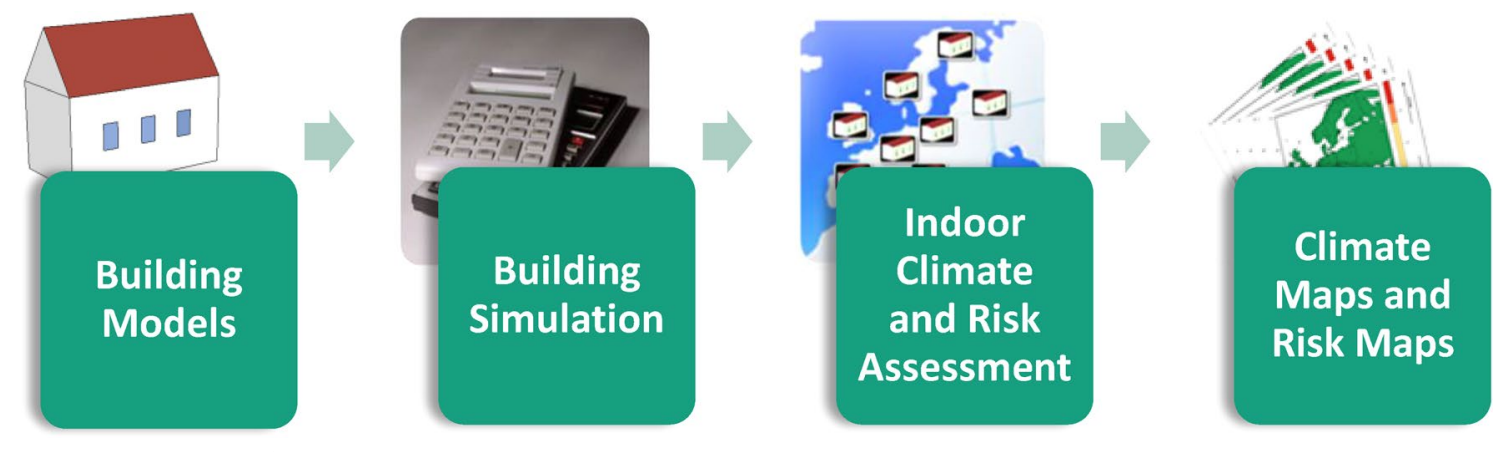

Fig. 7 Map-creation process from modelling buildings to risk maps

\begin{tabular}{|c|c|c|c|c|c|}
\hline & \multicolumn{2}{|c|}{ Heavyweight Building } & \multicolumn{2}{|c|}{ Lightweight Building } \\
\hline & & Low MB & High MB & Low MB & High MB \\
\hline \multirow{2}{*}{$\begin{array}{l}\text { Small } \\
\text { Building }\end{array}$} & $\begin{array}{l}\text { Small } \\
\text { Window } \\
\text { Area }\end{array}$ & & & & \\
\hline & $\begin{array}{l}\text { Large } \\
\text { Window } \\
\text { Area }\end{array}$ & & & & \\
\hline \multirow{2}{*}{$\begin{array}{l}\text { Large } \\
\text { Building }\end{array}$} & $\begin{array}{l}\text { Small } \\
\text { Window } \\
\text { Area }\end{array}$ & & $\begin{array}{llll}0 & 0 & 0\end{array}$ & & all \\
\hline & $\begin{array}{l}\text { Large } \\
\text { Window } \\
\text { Area }\end{array}$ & & प0ก & & प000์ \\
\hline
\end{tabular}

Fig. 8 Different generic building types (MB moisture buffering capacity)

range are calculated for both time-scales. Damages to the building interior and objects inside the buildings are often related to high levels or fluctuations in indoor temperature and relative humidity. Damage functions and risk thresholds can be used to describe the damage processes and give advice about possible dangers coming from indoor climate conditions. Thus, existing damage functions and risk thresholds were identified and associated to three types of damage: Biological, chemical and mechanical damage. For some damage functions available risk thresholds could be used for a risk categorisation into small, medium and high risks [31].

The above described evaluation methods for indoor climate variables and damage functions allow an assessment on an annual, seasonal and monthly time-scale. As the simulations of the generic sacred buildings cover a time-span of 31 years, a methodology for a long-term assessment had to be developed: For every simulated year all indoor climate variables, the damage functions and risk categories are assessed independently [17]. Subsequently, the assessment results for every parameter are averaged, resulting in a characteristic value representing the time-span like for example the average annual salt-crystallization cycles or the average indoor temperature for the month August. To allow an averaging of the risk categories, these are translated into numeric values: Small risk is represented with "0", medium risk with " 1 " and high risk with " 2 ". After averaging, the resulting value gives a long-term tendency towards a risk category.

The assessment has been performed for 474 locations which are distributed on a regular grid across Europe and the Mediterranean area, see Fig. 2. The assessments for the long-term damage risks and the indoor climate are applied to every location. Their results are the basis for the pan-European maps, which display the results of the risk assessment. Furthermore the changes between the 

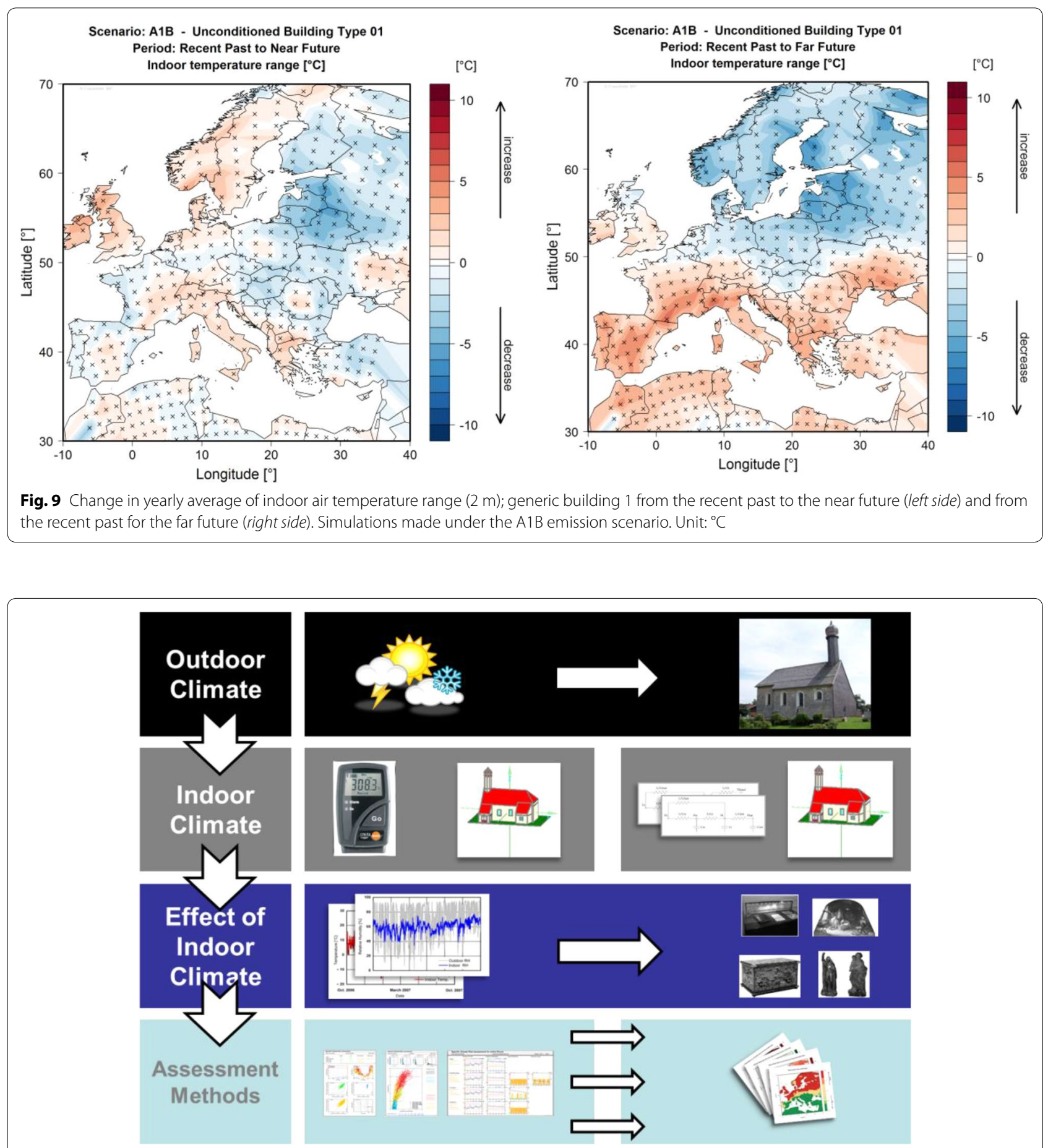

Fig. 10 Climate for Culture procedure for automated risk/damage assessment and risk maps

time periods are also calculated and visualised as maps. The recent past serves as baseline for each of the two future periods.

A number of results are related to the simulation of mechanical, biological and chemical risks concerning nine selected materials used or kept in the building interiors. Figure 11 highlights the mechanical risk for marble, stone and masonry due to future change in the frequency of salt crystallization cycles per year. Here, following definitions of risk were applied: 


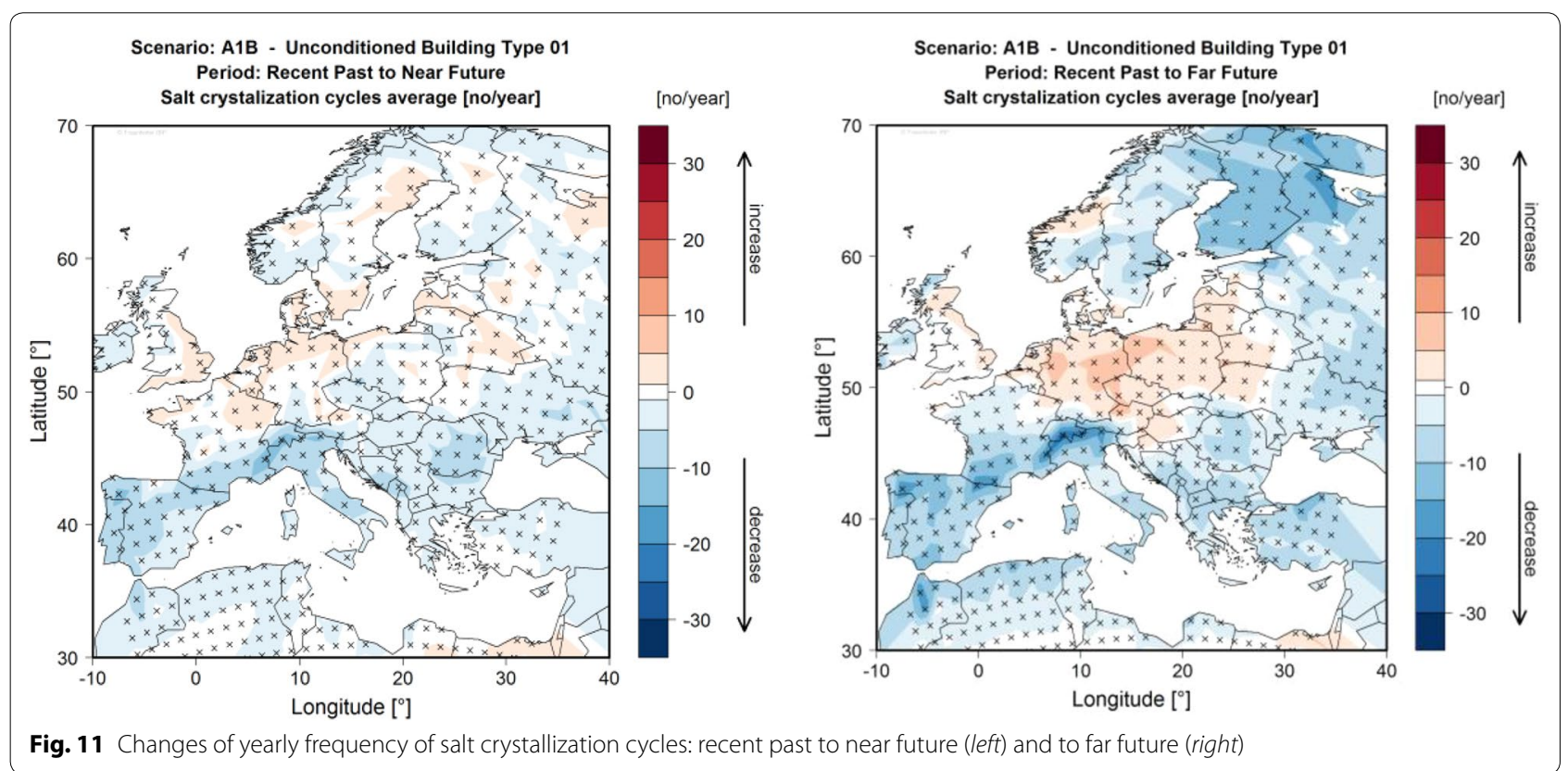

Risk $=$ (probability of finding a certain number of cycles) $\times$ (specific damage calculated with the damage function for each particular material)] which is the same as $[$ Risk $=($ calculated frequency of cycles $) \times($ damage for a single cycle calculated with the damage function for each particular material)]. Climate change will only affect the calculated frequency of crystallization. For each material, the ratio between the damage that will occur in a selected 30 year period (e.g. Near Future, Far Future) and the damage occurred in a certain reference period (e.g. 1961-1990) equals the ratio of the two calculated frequencies. It is thus possible to establish future tendencies, i.e. whether the damage is likely to increase, remain unchanged, or decrease, irrespective of the particular material type.

Figure 11 left shows for the near future under the A1B emission scenario, mixed situations in Northern Europe and the Mediterranean Area with changes ranging from (-) 20 cycles/year, in the Alps and in large part of Northern Europe, up to $(+) 10$ cycles/year respect to the recent past in the rest of Northern Europe, Southern Mediterranean and Spanish coast. In the far future (Fig. 11, right), the simulation shows larger changes, i.e. in the Northern region and on the Alps a decrease up to (-) 40 cycles/ year of salt crystallization cycles and consequently less risk for mechanical damages on masonry and stones is predicted. In contrast, the salt-crystallization cycles increase in frequency at around ( + ) 10 cycles/year in the rest of Europe.

Changing climate conditions also will affect biological activity in historic buildings and on cultural heritage materials. Fungal growth is a widespread problem with implications for or human health and the integrity of heritage material. The effects on heritage items can vary from a light powdery dusting to severe staining, weakening and disintegration of substrate material. Many deterioration processes are accompanied by biochemical transformations that occur only at certain temperatures, in the growing phase as well as in the development phase of the organism.

The most important factors are thus temperature, humidity and the nature of the substrate. It is assumed that mould spores are ubiquitous. At temperatures above $0{ }^{\circ} \mathrm{C}$ and humidity levels above $70 \% \mathrm{RH}$ mould spores can germinate. The time to germination decreases as temperature and humidity rise. Most fungi grow in a temperature range from 0 to $50^{\circ} \mathrm{C}$, whereby the tolerance to low temperatures is better than to high temperatures in this range. Biological activity depends on temperature and a certain minimum humidity is required for growth at which not the total moisture, but the "free" available water is considered. This part is called water activity and is only the part of the water, which is not bound by soluble substances (such as salts, carbohydrates, or proteins). The water content of the substrate depends further on the chemical composition, the temperature and the $\mathrm{pH}$ value of the substrate. Good growth conditions can be found not only whenever condensate is found at or on the material, but also at high relative humidity. Mould growth requires a certain minimum temperature to be active. To calculate the risk of mould growth the Sedlbauer isopleths system [32] has been used to generate the 
maps that show simulated risks in the recent past, near future and far future.

There is a widely accepted mould risk index based on visual examination with discrete categories from 0 to 6 $[33,34]$.

\section{0 : no growth}

1 : some growth detected only with microscopy

2: moderate growth detected with microscopy (coverage more than $10 \%$ )

3: some growth detected visually

4: visually detected coverage more than $10 \%$

5: visually detected coverage more than $50 \%$

6: visually detected coverage $100 \%$

Mathematical modelling allows the mould index to be treated as a continuous variable rather than a series of discrete steps. The growth rate output of Sedlbauer's biohygrothermal model has been correlated with the mould index [35]. Risk levels have been arbitrarily set at points on this continuum.

A mould index of less than 0.5, equivalent to a growth rate of less than $50 \mathrm{~mm} /$ year is considered safe (shown on the maps as green). If the mould index is between 0.5 and 2, equivalent to growth rates of between 50 and $200 \mathrm{~mm} /$ year, this indicates possible damage (shown as orange). A mould index greater than 2 , is an indication annual growth rates greater than $200 \mathrm{~mm}$ which are considered likely to cause damage (shown as red) [36]. In Fig. 12 the mould growth risk for the near and far future are displayed. The maps highlight that above $50^{\circ}$ latitude the damage potential of mould growth will increase, particularly in the last few years of this century.

\section{Modelled indoor climates and future energy demand of the historic building Amerongen Castle}

Historic buildings usually show elevated indoor humidity levels and a high variation of the climatic conditions, which can be dangerous to cultural heritage materials. This requires the detailed consideration of all hygrothermal interactions between the indoor air, the usage, the furnishing and the building envelope. The hygrothermal behaviour of a building component exposed to weather is an important aspect of the overall performance of a building. The calculation of the hygrothermal performance of a part of the envelope is state-of-the-art and a realistic assessment of all relevant effects can be carried out, but until now the total behaviour of the actual whole building is not accounted for. Questions which were addressed within this project:

How much ventilation and additional heat energy is required to ensure safe indoor conditions for cultural heritage when a historic building is exposed to extreme climate conditions or up to thousands of visitors per day? What will happen to the hygrothermal behaviour of walls and ceiling when a historic cellar is changed in its use and is turned for example into a restaurant? How do the indoor air conditions and the envelope of buildings with temporary use react to different heating and ventilation

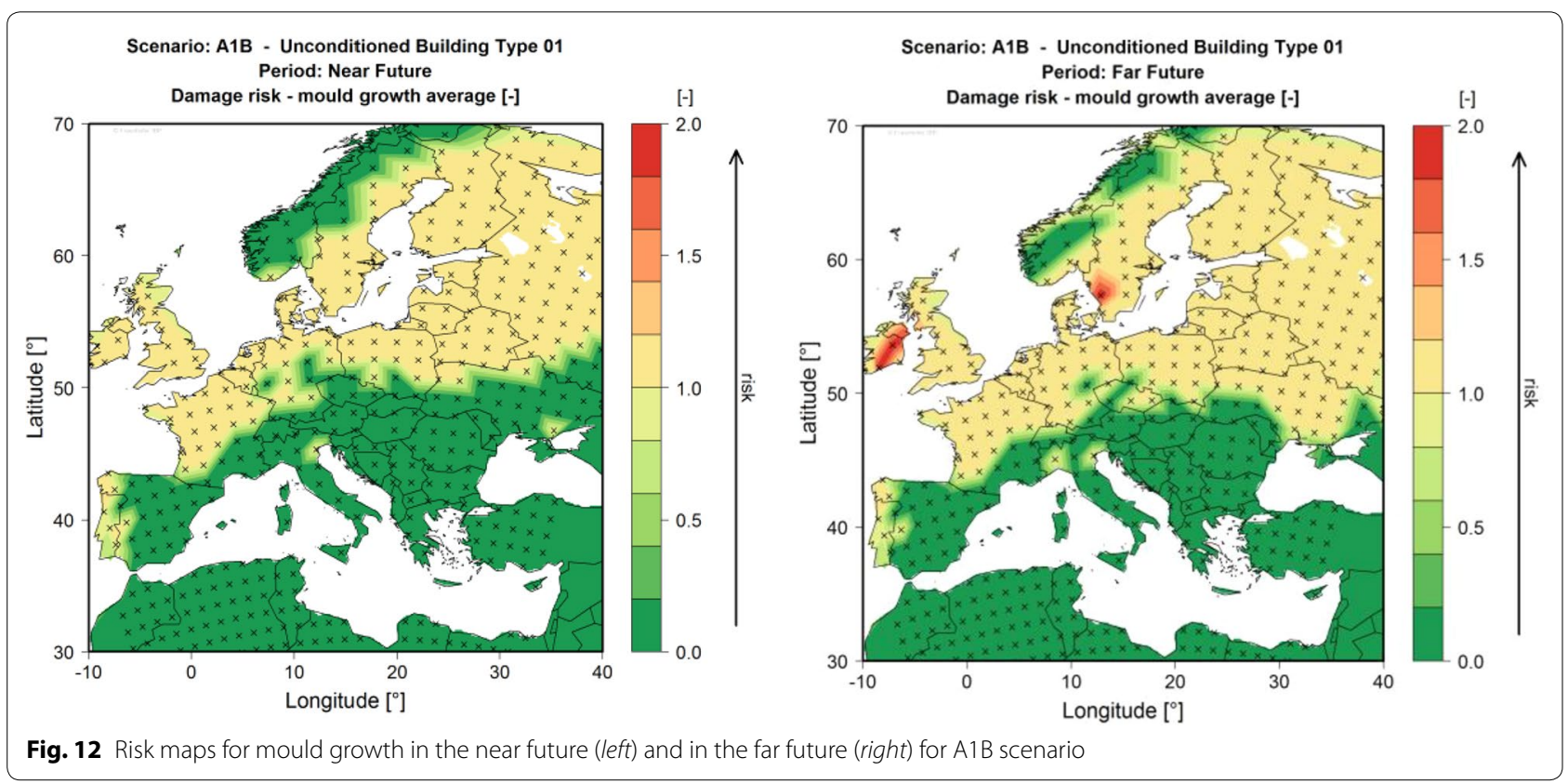


strategies? Can sorptive finish materials improve and stabilise the microclimate in historic buildings?

\section{Case study: Amerongen Castle}

Amerongen Castle, a Dutch state monument, was built in the 17th century. The building currently functions as a museum and accommodates a collection of valuable furniture and paintings. The building is characterised by high masonry walls with a thickness varying between 0.7 and $1.5 \mathrm{~m}$ and single glazed windows and exterior shutters. In recent years the indoor environment in the exhibition rooms has been hygrostatically controlled by a floor heating system. In the past, the building remained mainly unheated. The multi-zone hygrothermal building simulation model HAMBase [6] was used to calculate the indoor temperature and $\mathrm{RH}$ inside the castle as a result of the outdoor climate conditions, the building properties, the climate control system and the building use. HAMBase characterizes the indoor climate by uniform values for radiant temperature, air temperature and $\mathrm{RH}$ per zone. This study focused on the indoor climate conditions in one of the main exhibition rooms within the castle: the Grand Salon. Constant values for the set points and capacity of the conservation heating system were used in the HAMBase model (Table 2). The HAMBase model was validated with on-site measurements from 1 January until 31 December 2012 (Fig. 13). It should be kept in mind that the capacity of the current heating system is not sufficient to maintain a minimum temperature of $15{ }^{\circ} \mathrm{C}$ during the whole year. Also, the minimum temperature set point in the room seems to have slightly been lowered during the winter months. Excluding this period, the model shows an adequate agreement with the measurements: the simulated indoor temperature is generally within a range of $2{ }^{\circ} \mathrm{C}$ from the measurements, the difference between simulated and measured $\mathrm{RH}$ is about $\pm 10 \%$ and the humidity ratio is predicted within a range of $\pm 1 \mathrm{~g} / \mathrm{kg}$ from the measurements.

Next, the HAMBase model was coupled with future outdoor climate data from the weather station near the site (distance: approximately $20 \mathrm{~km}$ ). The future outdoor climate data were based on the IPCC A1B emission

Table 2 Set points and capacity of conservation heating system

\begin{tabular}{ll}
\hline Variable & Value \\
\hline Minimum temperature set point for conservation heating & $15^{\circ} \mathrm{C}$ \\
Maximum temperature set point for conservation heating & $22^{\circ} \mathrm{C}$ \\
Minimum RH set point for conservation heating & $40 \%$ \\
Maximum RH set point for conservation heating & $70 \%$ \\
Maximum heating capacity & $1000 \mathrm{~W}$ \\
\hline
\end{tabular}

scenario. The predicted indoor temperature, humidity ratio and annual energy demand for heating were compared for the years 1960, 1970, 1980, 1990, 2020, 2030, 2040, 2050, 2070, 2080, 2090 and 2100. Figure 14 shows the average indoor temperatures in winter and summer. The difference between the average conditions for the recent past and far future is clearly more significant than the differences between recent past and near future. However, the future outdoor climate data of for the far future have a higher uncertainty than the near future data. It can be seen that the average winter temperature may slightly increase from $11{ }^{\circ} \mathrm{C}$ in the recent past to $13{ }^{\circ} \mathrm{C}$ in the far future. A similar temperature increase is predicted in summer: in the recent past the average summer temperature was about $20^{\circ} \mathrm{C}$, while in the far future an average summer temperature of $22{ }^{\circ} \mathrm{C}$ is predicted. The average humidity ratio may slightly increase by $1 \mathrm{~g} /$ $\mathrm{kg}$ in winter and $1.5 \mathrm{~g} / \mathrm{kg}$ in summer (Fig. 15). On average, the annual energy demand for heating the room may slightly decrease in future by approximately $350 \mathrm{kWh}$ (Fig. 16).

The results indicate that indoor temperatures above $25{ }^{\circ} \mathrm{C}$ could occur more frequently in future (Fig. 17). Additionally, the hygrostatically controlled heating system may not be appropriate in future summer periods when both indoor temperature and absolute humidity rise. Additional measures should be taken to avoid overheating risks and decrease humidity levels.

\section{Conclusions}

A new methodology has been developed to assess not only outdoor risks to cultural heritage assets, but also risks for indoor collections resulting from climate change. This can be done not only for individual buildings, but also on a larger scale in the form of risk maps: Altogether 55,650 thematic maps have been created. These address future outdoor and indoor climates until the year 2100, risks to cultural heritage objects such as mould growth or insect pests, and future energy demand for climate control in historic buildings. The maps can be produced using a generic building approach with an automated procedure. By using different artificial buildings as standard examples in modelling climate change impact, a comparison between different regions in Europe has become possible for the first time. The calculations have been done with two different methods, using transfer functions for a state space model or more elaborate whole building simulation models. Additionally, sustainable and energy-efficient mitigation and adaptation solutions based on the project methodology were tested and further developed. They used mathematical models of object responses to indoor-climate variations. Many of the results obtained are integrated into the decision 

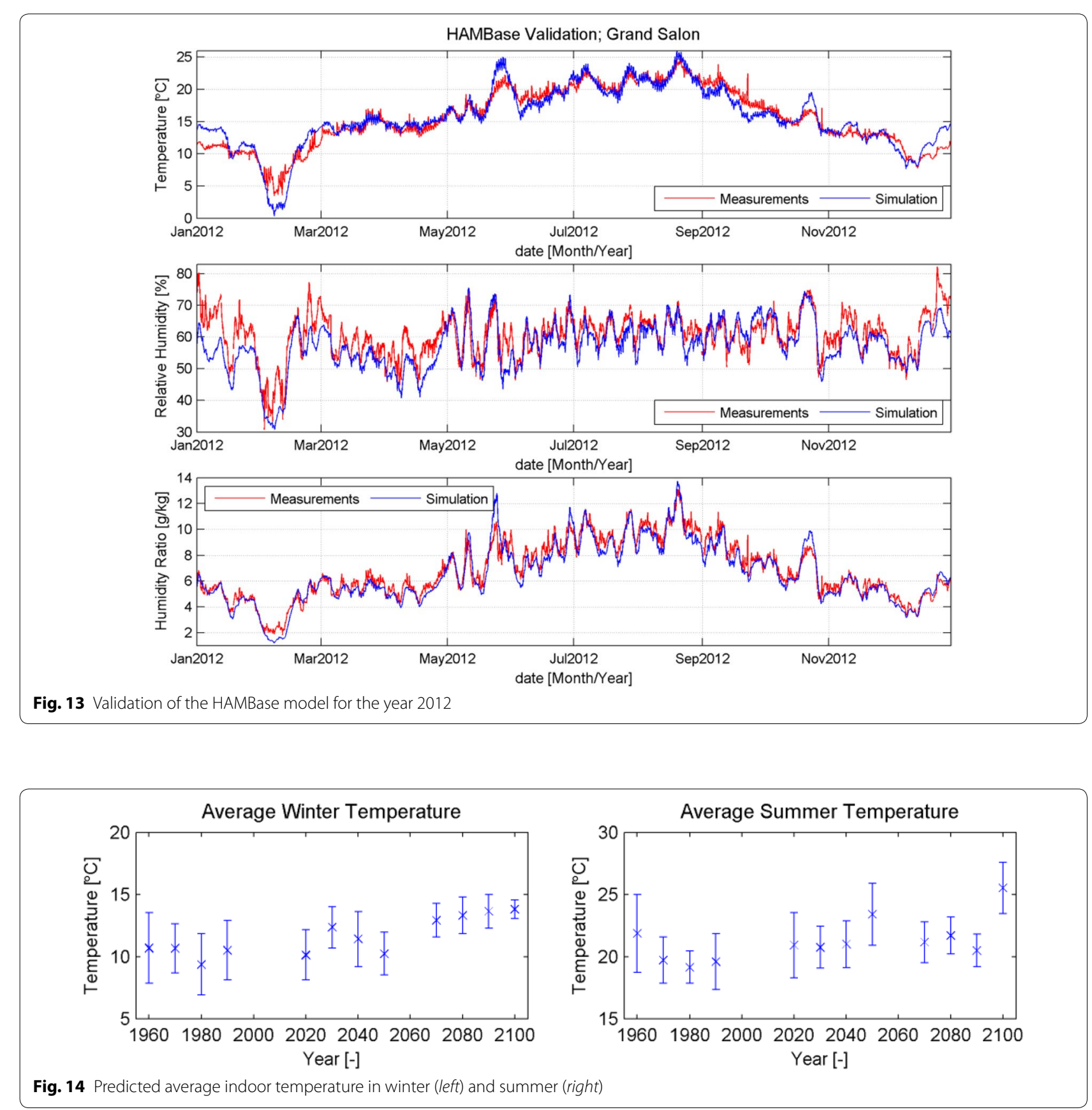

support systems DMSS and ExDSS [37], offering useful information for heritage owners and the interested public. Although the final level of uncertainty in the risk maps will be high regardless of whether a deterministic or a probabilistic approach is used, risk maps based on state-of-the-art scientific knowledge are valuable as 

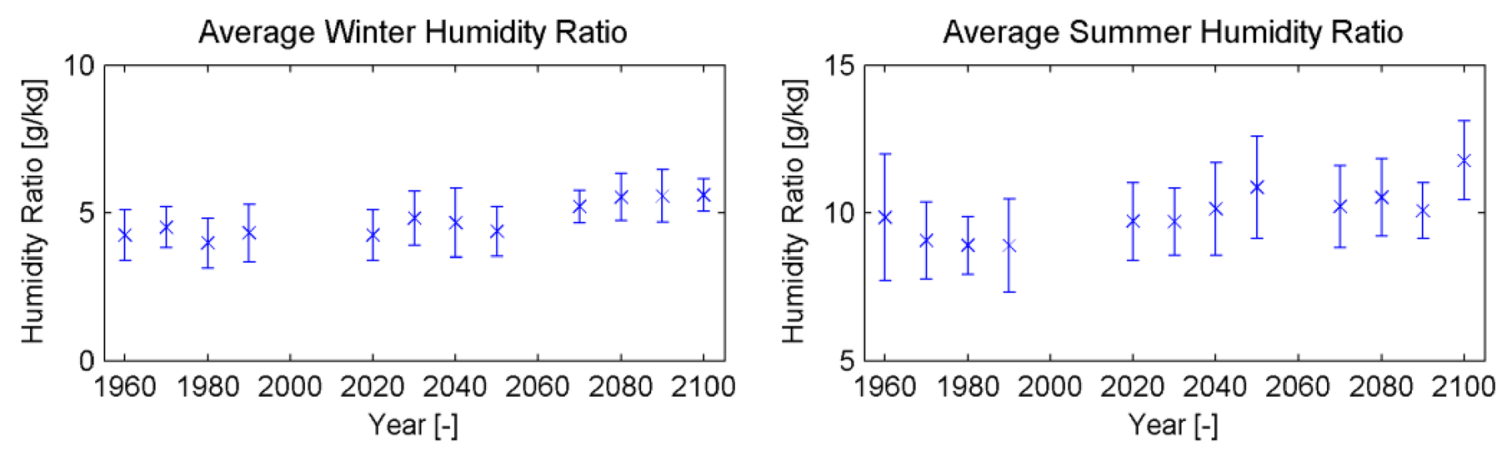

Fig. 15 Predicted average indoor humidity mixing ratio in winter and summer

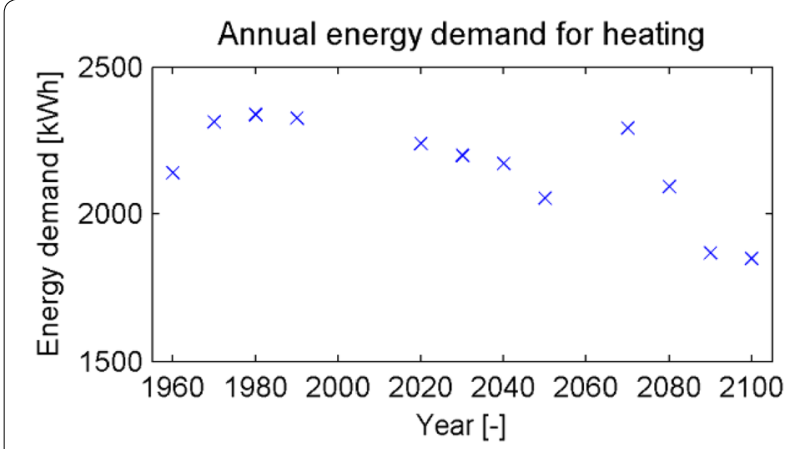

Fig. 16 Predicted annual energy demand for heating

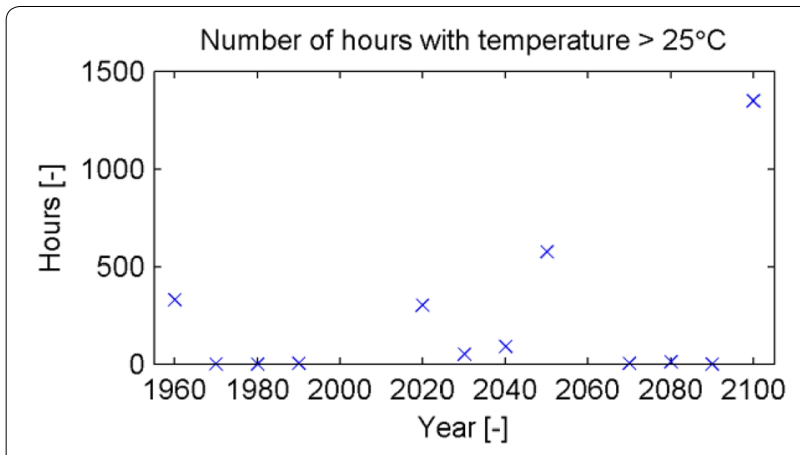

Fig. 17 Predicted number of hours per year with indoor temperatures exceeding $25^{\circ} \mathrm{C}$

indicators of future risks to cultural heritage. They can play an important role as a decision tool helping to plan more effective mitigation and adaption measures at various levels.

\section{Authors' contributions}

All authors have contributed evenly to the results described in the publication. All authors read and approved the final manuscript.

\section{Author details}

${ }^{1}$ Fraunhofer Gesellschaft, Hansastrasse 67c, 80686 Munich, Germany. ${ }^{2}$ Climate Service Center 2.0, Helmholtz Center Geesthacht, Fischer Twiete1, 20095 Hamburg, Germany. ${ }^{3}$ Max Planck Institut für Meteorologie, Bundesstraße 53, 20146 Hamburg, Germany. ${ }^{4}$ Uppsala University, Campus Gotland, Cramérga$\tan$ 3, 62157 Visby, Sweden. ${ }^{5}$ Barton Road, Cambridge CB3 9BB, UK. ${ }^{6}$ Technical University Eindhoven, 5612 AZ Eindhoven, The Netherlands. ${ }^{7}$ CNR-ISAC Padova, Corso Stati Uniti 4, 35127 Padova, Italy. ${ }^{8}$ Czech Technical University in Prague, Zikova 1903/4, 16636 Prague 6, Czech Republic.

\section{Acknowledgements}

The authors would like to thank the whole project team for their hard work and enthusiasm during the last five years. Only a few of the results have been presented here. Altogether around 90 scientists from 16 countries have worked on the project. We are also very grateful to the European Commission/DG Research and Innovation for funding the "Climate for Culture" project within the Seventh Framework Programme for Research under Grant Agreement No. 226973.

\section{Competing interests}

The authors declare that they have no competing interests.

Received: 28 May 2015 Accepted: 24 November 2015

Published online: 11 December 2015

\section{References}

1. Climate for Culture: http://www.climateforculture.eu. Accessed 21 Oct 2015.

2. Kilian R, Leissner J, Antretter F, Holl K, Holm A. Modelling climate change impact on cultural heritage-The European project Climate for Culture. In: BunnikT et al, editors Effect of climate change on built heritage. Pfaffenhofen: WTA Publications, Vol., 34, 2010. p. 131-143.

3. Climate for Culture: Public Deliverables for WP1, WP3, WP4, WP5, WP7. http://www.climateforculture.eu/index.php?inhalt=furtherresources. projectresults. Accessed 19 Oct 2015.

4. Jacob D, Elizalde A, Haensler A, Hagemann S, Kumar P, Podzun R, Rechid D, Remedio AR, Saeed F, Sieck K, Teichmann C, Wilhelm C. Assessing the transferability of the regional climate model REMO to different coordinated regional climate downscaling experiment (CORDEX) regions. Atmosphere. 2012;3:181-99.

5. IPCC SRES. In: Nakicenovic N, Swart R, editors. Special Report on Emissions Scenarios: a special report of Working Group III of the Intergovernmental Panel on Climate Change. UK: Cambridge University Press, 2000.

6. Towards new scenarios for analysis of emissions, climate change, impacts and response strategies. Technical summary, IPCC expert meeting report 
2007; https://www.ipcc.ch/pdf/supporting-material/expert-meeting-tsscenarios.pdf. Accessed 2 Apr 2015.

7. Bichlmair S, Kilian R, Krus M: Concept of a new airing strategy and simulation of the expected indoor climate in Linderhof Palace. In: CLIMA 2013:

11 th REHVA World Congress 0\& 8th International Conference on IAQVEC; Energy Efficient, Smart and Healthy Buildings; 2013, Prague: Czech Republic.

8. Antretter F, Kilian R. WUFI ${ }^{\circledR}$ PLUS: Werkzeuge zur Vorhersage des hygrothermischen Raumklimas in historischen Gebäuden. Restauro. 2014;120:42-3.

9. de Wit M. Hambase, Heat, air and moisture model for buildings and systems evaluation. Eindhoven University Press 2006. 2008; ISBN 90-6814601-7 http://sts.bwk.tue.nl/hamlab/readers/bouwsteen100.pdf. Accessed 13 Apr 2015.

10. van Schijndel AWM. A review of the application of SimuLink S-functions to multi domain modeling and building simulation. J Building Perform Simul. 2014;7(3):165-78.

11. Lengsfeld K, Holm A. Entwicklung und Validierung einer hygrothermischen Raumklima-Simulationssoftware WUFF ${ }^{\circledR}$ Plus. Bauphysik. 2007;29:178-86.

12. Kilian R: Klimastabilität historischer Gebäude. Bewertung hygrothermischer Simulationen im Kontext der Präventiven Konservierung. Dissertation, Universität Stuttgart, 2013.

13. Kramer RP, van Schijndel AWM, Schellen HL. Inverse modeling of simplified hygrothermal building models to predict and characterize indoor climates. Build Environ. 2013;68:87-99.

14. Lankester P, Brimblecombe P. Future thermohygrometric climate within historic houses. J Cult Herit. 2012;12:1-6.

15. Earth's $\mathrm{CO}_{2}$ Home Page. http://co2now.org/current-co2/co2-now/earthshome-page-for-atmospheric-co2.html. Accessed 2 Apr 2015.

16. IPCC: Climate Change 2014: Synthesis Report. Contribution of Working Groups I, II and III to the Fifth Assessment Report of the Intergovernmental Panel on Climate Change; Geneva, Switzerland. http://ipcc.ch/report/ ar5/syr/. Accessed 2 Apr 2015.

17. Bertolin C, Camuffo D. Deliverable 5.2 Climate change impact on movable and immovable cultural heritage throughout Europe; 2014:15-18. http://www.climateforculture.eu/index.php?inhalt=furtherresources. projectresults. Accessed 21 Oct 2015.

18. Winkler M. Development of an automated damage risk assessment method for the evaluation of the climate change impact on historic buildings and their interiors in Europe. Master's Thesis. University of Applied Sciences Munich; 2013.

19. Huijbregts Z, Kramer RP, Martens MHJ, van Schijndel AWM, Schellen HL. A proposed method to assess the damage risk of future climate change to museum objects in historic buildings. Build Environ. 2012;55:43-56.

20. Livingston, RA: Development of Air pollution damage functions. In: Baer NS, Snethlage R, editors. Saving our architectural heritage: The conservation of historic stone sculptures. New York: John Wiley 1996. p. 37-62.

21. Brimblecombe P, Grossi CM. Millennium-long damage to building materials in London. Sci Total Environ. 2009;407:1354-61.

22. Sabbioni C, Brimblecombe P, Cassar M. The atlas of climate change impact on European cultural heritage: scientific analysis and management strategies. Anthem Press; 2012.
23. Vereecken E, Roels S. Review of mould prediction models and their influence on mould risk evaluation. Build Environ. 2012;51:296-310.

24. Bratasz L: Acceptable and non-acceptable microclimate variability: the case of wood. In: Camuffo D, Fassina V and Havermans, editors. Basic environmental mechanisms affecting cultural heritage. Understanding deterioration mechanisms for conservation process, COST Action D 42. Chemical interactions between cultural artefacts and indoor environment. 2010. p. 49-58.

25. Luxford N, Strlic M, Thickett D. Safe display parameters for veneer and marquetry objects: a review of the available information for wooden collections. Stud Conserv. 2013;58(No1):1-12.

26. Bratasz L. Allowable microclimatic variations for painted wood. Stud Conserv. 2013;58(2):65-79.

27. Brimblecombe P, Grossi CM. Potential damage to modern building materials from 21st century air pollution. Scient World J. 2010;10:116-25.

28. Bonazza A, Messina P, Sabbioni C, Grossi CM, Brimblecombe P. Mapping the impact of climate change on surface recession of carbonate buildings in Europe. Sci Total Environ. 2009;407:2039-50.

29. Menart E, De Bruin G, Strlic M. Dose-response functions for historic paper. Polym Degrad Stab. 2011;96:2029-39.

30. Ashley-Smith J : Deliverable 4.2 Report on damage functions in relation to climate change; 2013;21-38 http://www.climateforculture.eu/index. php?inhalt=furtherresources.projectresults. Accessed 21 Oct 2015.

31. Martens MHJ. Climate risk assessment in museums: degradation risks determined from temperature and relative humidity data. Dissertation. Eindhoven University of Technology; 2012.

32. Sedlbauer K. Prediction of mould fungus formation on the surface of and inside building components. Fraunhofer Institute for Building Physics, Holzkirchen, Germany; 2001. http://www.ibp.fraunhofer.de/content/ dam/ibp/en/documents/ks_dissertation_etcm1021-30729.pdf; Accessed 2 Apr 2015.

33. Viitanen H, Ojanen, $\mathrm{T}$ : Improved Model to Predict Mold Growth in Building Materials. ASHRAE, 2007.

34. Ojanen T et al: Mold growth modeling of building structures using sensitivity classes of materials. ASHRAE, 2010.

35. Krus M, Seidler CM, Sedlbauer K: Comparative evaluation of the predictions of two established mold growth models. ASHRAE Buildings XI Conference, 2010.

36. Krus M, Seidler CM, Sedlbauer K: Übertragung des Mould-Indexes auf das Biohygrothermische Modell zur Schimmelpilzvorhersage. Gesundheitsingenieur 2011, 132(Heft 1): 32-36.

37. Climate for Culture decision support system ExDSS. http://cfc.exdss.org/ dss/riskcon. Accessed 15 Apr 2015.

\section{Publish with ChemistryCentral and every scientist can read your work free of charge \\ "Open access provides opportunities to our colleagues in other parts of the globe, by allowing anyone to view the content free of charge."}

W. Jeffery Hurst, The Hershey Company.

- available free of charge to the entire scientific community

- peer reviewed and published immediately upon acceptance

- cited in PubMed and archived on PubMed Central

- yours - you keep the copyright

Submit your manuscript here:

http://www.chemistrycentral.com/manuscript/ 